
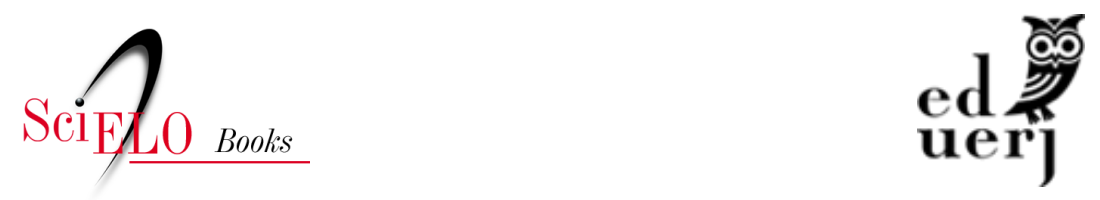

\title{
Capítulo II - Fazenda do Engenho Novo: história e patrimônio em São Gonçalo
}

Rui Aniceto Nascimento Fernandes

\section{SciELO Books / SciELO Livros / SciELO Libros}

FERNANDES, R. A. N. Fazenda do Engenho Novo: história e patrimônio em São Gonçalo. In: SANTOS, M. G., ed. O rural em regiões metropolitanas: a Fazenda Engenho Novo, São Gonçalo [online]. Rio de Janeiro: EDUERJ, 2020, pp. 29-46. ISBN: 978-65-00-03030-3. https://doi.org/10.7476/9786500030303.0004.

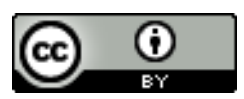

All the contents of this work, except where otherwise noted, is licensed under a Creative Commons Attribution 4.0 International license.

Todo o conteúdo deste trabalho, exceto quando houver ressalva, é publicado sob a licença Creative Commons Atribição 4.0.

Todo el contenido de esta obra, excepto donde se indique lo contrario, está bajo licencia de la licencia Creative Commons Reconocimento 4.0. 


\title{
Capítulo II \\ Fazenda do Engenho Novo: história e patrimônio em São Gonçalo
}

\author{
Rui Aniceto Nascimento Fernandes
}

A Fazenda do Engenho Novo foi e é conhecida por vários nomes: Engenho Novo do Retiro, Engenho Novo do Bom Retiro, Fazenda do Barão e Fazenda do Serrado. Por um longo período, esse sítio histórico foi relegado à ação do tempo, de caçadores de tesouros e de vândalos que promoveram o arruinamento dos prédios seculares. Nos últimos tempos, a partir da ação do Estado, as atençóes da sociedade local se voltaram para aquele espaço. Na verdade, a Fazenda sempre foi considerada um bem importante entre aqueles que se esforçaram por constituir uma identidade positivada para o gonçalense. Ao longo do tempo, a historiografia local tornou-a relevante por ter sido propriedade de Belarmino Ricardo de Siqueira, o barão de São Gonçalo, e, com isso, ter incluído o município entre a nobiliarquia e a Casa Imperial brasileira, pela proximidade que esse titular do império tinha com D. Pedro II. Esse era um elemento de dignificação local que mostrava que São Gonçalo foi importante no passado por ter sido o espaço que abrigou o imperador Pedro II, algumas vezes em visitas ao barão. Este texto, por outro lado, segue uma direção diferente. Serão apresentados levantamentos e questionamentos iniciais de uma pesquisa em curso, que objetiva problematizar as experiências históricas vivenciadas naquele espaço e como estas o constituíram como um patrimônio cultural local. 


\section{A Fazenda do Engenho Novo como um lugar de histórias}

O que transforma um prédio antigo em prédio histórico? A antiguidade da construção não é por si só um requisito para lhe dar significação social que justifique sua preservação e o transforme em patrimônio. As construçóes arquitetônicas devem ser compreendidas como partes de cenários em constante transformação ao longo do tempo. Como tais, elas são testemunhas silenciosas de fatos ocorridos ao seu redor. Igrejas, prédios públicos, sedes de fazendas, fábricas, entre outras construçóes, ajudam a compor os espaços rurais e urbanos, constituindo-se em registros de cultura material. Logo, o estudo dessas construçóes no tempo, levando em consideraçáo seus diversos usos e funçôes, permite compreender melhor as mudanças e as permanências ocorridas em uma localidade. Além disso, conhecer como os homens de diferentes tempos representaram os lugares nos oferece elementos preciosos sobre as formas peculiares de ver esses lugares em cada tempo (Conduru et al., 2013, pp. 7-35).

A Fazenda do Engenho Novo é considerada elemento relevante e dignificador da localidade na produção historiográfica sobre São Gonçalo. Ela é mencionada em grande parte dos estudos sobre a cidade que foram produzidos ao longo do século XX como um importante sítio histórico (Palmier, 1940; Guião Filho, 1968; Braga, 1997). Produzida por pesquisadores locais, essa historiografia está comprometida com a formaçáo de uma identidade positivada para a cidade. Esses estudiosos, em geral, seguem modelos historiográficos propugnados por associaçóes culturais como Institutos Históricos e Academias de Letras, onde se valoriza uma história epopeica, heroica, biográfica dos feitos e fastos gloriosos. Os vestígios materiais do passado são elementos supervalorizados como forma de concretizar os feitos daqueles que viveram nos espaços que hoje compóem a localidade e que sinalizam sua importância em outros tempos (Reznik, 2002; Fernandes, 2009). 
É uma historiografia preocupada com os processos de crescimento urbano-populacional pelo qual o município passou desde a década de 1950 e que o transformou em uma cidade de mais de um milhão de habitantes, com sérios problemas de infraestrutura e ambientais (Freire, 2002).

Nesse universo, destacam-se dois livros que se detêm mais amiúde sobre nosso objeto. O primeiro, datado de 2000, é o trabalho de Nilda Ferreira Mendes Filha e Marcos Vinicius Macedo Varella: São Gonçalo, sua história e seus monumentos (Mendes Filha $\&$ Varella, 2000). Não se trata de um estudo específico sobre a Fazenda do Engenho Novo, como seu próprio título indica, mas foca no registro dos monumentos históricos de São Gonçalo. Para cada monumento há um capítulo específico e, entre eles, há um dedicado à Fazenda do Engenho Novo. Os autores arrolam uma série de informaçóes sobre o Barão de São Gonçalo - especialmente coletados de seu testamento -, uma descriçâo das construçóes e sobre os sucessivos proprietários. Incorporam ainda uma série de imagens das construçóes que pertenciam à propriedade.

$\mathrm{O}$ único trabalho exclusivamente dedicado à Fazenda do Engenho Novo também foi escrito por uma dupla, Evadyr Molina e Salvador Mata e Silva: A Fazenda do Engenho do Retiro (Molina e Silva, 2001). Em grande parte baseado no testamento do Barão de São Gonçalo, o estudo busca historiar os proprietários - destacando o barão e o Coronel Joaquim Serrado - e dá grande relevo ao inventário de objetos que constituiu o acervo da sede e da capela de Nossa Senhora da Conceição. Um outro tema caro aos historiadores era a vinculação do barão à maçonaria. Para tal, transcreveram dois textos de Vieira Fazenda sobre o tema. Por fim, há um conjunto de imagens sobre as construçóes e da família do Coronel Serrado.

Ambos os trabalhos tomam como ponto de partida a relevância histórica das construçôes como patrimônio local. Não há um questionamento ou análise do processo de patrimonialização pelo qual o bem passou no Instituto Estadual do Patrimônio Cul- 
tural (INEPAC) do Rio de Janeiro, por exemplo. Ou, para fugirmos dos princípios de oficialização do patrimônio, como aquela comunidade se relacionaria com tal bem.

Em geral, essa produção destaca a importância do bem não pelas experiências históricas ali vivenciadas, mas por ele ter pertencido a dois potentados locais: o Barão de São Gonçalo e o Coronel Serrado. Mais do que destacar as características estilísticas do conjunto arquitetônico, o seu papel na estrutura econômica local ao longo do século XIX e XX, as disputas pela posse da terra; essas análises consideram que a Fazenda é um patrimônio e deve ser preservada por ser uma das mais antigas ainda em pé, à época de suas redaçóes, e por ter acolhido o imperador Pedro II e a família imperial ao menos uma vez. É o fetiche antiquário do passado pelo passado (Momigliano, 2004; Guimarães, 2000).

Há uma pequena, mas relevante, produção acadêmica abordando diferentes temáticas que envolvem as experiências históricas ali vivenciadas. A monografia de especialização lato sensu, de Alessandra Furtado de Oliveira Novais, analisa a figura do Barão de São Gonçalo no cenário da nobreza fluminense do século XIX e destaca o imaginário vinculado à morte analisando os ritos funerários de Belarmino Ricardo de Siqueira (Novais, 2000).

Os trabalhos de pesquisa de Karla Estelita Godoy e Cristiane Valladares de Azevedo analisam como a Fazenda constituiu-se elemento relevante no processo de constituição da identidade local investigando a relação entre história e memória nos depoimentos dos moradores da área. Por outro lado, fixam perspectivas de como a consolidação e preservação das ruínas dos prédios podem integrar um circuito turístico que se associe às práticas de um "turismo improvisado" que já é realizado entre os sitiantes da área da antiga fazenda (Azevedo e Godoy, 2009 e 2012; Godoy, 2011).

Raiane Almeida de Oliveira tem como principal fonte de pesquisa, em sua dissertação de mestrado, o inventário do Barão de São Gonçalo. Com esse volumoso documento - são mais de 
500 páginas -, seu recorte de estudos é a questão da família escrava no século XIX (Oliveira, 2012).

A monografia de graduação de Klícia Alves Pereira Motta insere o processo de tombamento do conjunto arquitetônico nas concepções e políticas públicas de patrimonialização no Brasil. Em sua análise, destaca similitudes e especificidades da ação do INEPAC frente à política nacional gestada pelo Instituto do Patrimônio Histórico e Artístico Nacional (IPHAN) (Motta, 2013).

O levantamento historiográfico realizado indica um potencial de pesquisa ainda pouco explorado. Uma das questôes que poderiam limitá-lo seria a das fontes primárias. A princípio poderíamos supor uma impossibilidade de trabalho por não haver um acervo documental organizado sobre a Fazenda. No entanto, bem já apendemos com toda a tradiçấo da crítica documental que o trabalho do historiador náo parte do documento (Le Goff, 2003). O estudioso inicia a partir de questóes/problemáticas e, assim, ele fixa o conjunto documental com o qual trabalhará. Nesse sentido, a ausência de documentação direta não inviabiliza certos trabalhos, pois é possível acessar informaçôes por meio de outras fontes. É dessa forma que os historiadores sociais vêm trabalhando com a cultura popular dos trabalhadores ingleses e franceses nos séculos XVII e XVIII, por exemplo, acessando relatos e documentos dos grupos hegemônicos (Thompson, 1998a; Michelet, 1989). Nesses termos, é necessário que elenquemos analiticamente períodos e temas possíveis para abordarmos as histórias vivenciadas naquele espaço rural.

A produção já existente se fundamenta especialmente no inventário do Barão de São Gonçalo, na bibliografia mencionada e em informaçóes prestadas por pessoas que viveram ou tiveram alguma ligação com o local.

Nesse sentido, revisitar o inventário é uma tarefa importante. Mas não apenas no sentido de conhecer os bens que pertenceram ao nobre barão. Seu testamento deve ser problematizado 
por questóes como a escravidão, a estrutura produtiva agrícola no século XIX, o sistema financiador e comercial, as relaçóes de dependência e familiares, a religiosidade etc. Essa pesquisa poderá cotejar outras fontes similares - testamentos e inventários de outros proprietários - assim como a imprensa local/regional do século XIX - atualmente facilitado pela hermeroteca digital da $\mathrm{Bi}$ blioteca Nacional. ${ }^{1}$ A imprensa também é um importante veículo de informaçóes para o século XX por registrar não só dados sobre as questóes econômicas - produção, estrutura fundiária, formas de trabalho -, mas também sociais - festividades, celebrações religiosas etc. As disputas pela posse da terra, na segunda metade do século XX, abrem uma nova vereda de pesquisa, por exemplo, com a consulta à documentação do sindicato rural. Para esse período, também é fundamental a história oral (Thompson, 1998b; Meihy, 2002). Por meio dos depoimentos é possível acessar memórias para além desse período, pois os guardióes da memória local podem ser herdeiros dos remanescentes de escravos do século XIX e detentores de saberes tradicionais no campo da produção de subsistência e do uso de ervas em sua medicina popular. ${ }^{2} \mathrm{~A}$ iconografia, que já aparece nos trabalhos citados, em geral, é utilizada como ilustração. Há de se problematizá-la pensando em seus contextos de produção e circulaçáo (Kossoy, 1980; Mauad, 1996). Há também um conjunto de imagens do interior do casarão na Coleção MEMOR, registradas na década de 1990, que nos permite pensar sobre os modos de viver da nobreza no século XIX. O processo de tombamento oficial, realizado pelo INEPAC, apesar

1 Nos últimos anos, a Biblioteca Nacional, no Rio de Janeiro, tem seguido uma politica internacional de acessibilidade ao seu acervo por meio da digitalização e da construçáo de uma base digital via web. Nesse sentido o acervo de periódicos - jornais, boletins, anuários, relatórios etc - vem sistematicamente sido digitalizado e disponibilizado em: http://bndigital.bn.br/hemeroteca-digital/. Acesso em 26 de agosto de 2015.

2 Essa temática vem sendo estudada por Luiz Henrique Marinho Lages como tema de sua dissertação de mestrado em desenvolvimento no mestrado profissional em Ensino de Ciências, Ambiente e Sociedade/UERJ. 
de já consultado, merece um estudo mais aprofundado inserindo-o nas concepçóes de patrimônio em voga no Brasil dos anos 1990 e na política de patrimonializaçáo do Estado do Rio de Janeiro, pós-fusão dos Estados do Rio de Janeiro e da Guanabara.

É possível, então, propor que a pesquisa sobre as experiências históricas vivenciadas no território da Fazenda do Engenho Novo seja norteada por três eixos/períodos.

Um primeiro momento poderia ser denominado de $A$ ocupação do sertão gonçalense (séculos XVII e XVIII). O território gonçalense passou a ser conquistado pela colonizaçáo lusa ainda no século XVI, após o episódio da França Antártica (1555-67). Após a vitória lusa, para consolidar o seu domínio na região guanabarina, a Coroa portuguesa projetou a ocupação desse território com a doação de sesmarias ao redor da Baía. A presença lusa no litoral estava consolidada no século seguinte quando os engenhos estavam formados, os homens bons - título dado à elite da época -, atuando politicamente, obtiveram a criaçáo da freguesia de São Gonçalo em 1644 e lideraram motim contra o governador do Rio de Janeiro, entre 1660-61, a chamada Revolta da Cachaça (Fernandes, 2006; Molina e Silva, 1995, 1997; Caetano, 2009).

A partir de meados do século XVII, inicia-se o processo de interiorização da colonização do território gonçalense com o avanço sobre o sertáo. Regiáo de fronteira fluida, o sertâo era a área ainda não ocupada (Lima, 1999). Entre 1673 e 1772, uma série de sesmarias foram doadas na regiáo que hoje corresponde aos atuais $2 .^{\circ}$ e $3 .^{\circ}$ distrito do município, Ipiíba e Monjolos (Molina e Silva, 1997 e 1998; Araújo, 1900). Essa é uma temática praticamente inexplorada. Os autores que se dedicaram ao período preocuparam-se com o inventário de fazendas/engenhos formados e com o levantamento de dados biográficos e genealógicos dos seus proprietários; não investiram num estudo sobre os processos de ocupação do sertão. 
O segundo período poderia ser definido como dos séculos XVIII e XIX e denominado de "a integração à sociedade mercantil escravista”. A partir da concessão de sesmarias, os engenhos são formados; passam a produzir não apenas a cana de açúcar, mas também víveres para o abastecimento interno e do mercado do Rio de Janeiro; importam escravos, constroem-se capelas. É nesse período que o sertáo gonçalense se integra à sociedade mercantil escravista.

A Fazenda do Engenho Novo teria sido criada antes de 1794 quando era propriedade de Ana e Luiza Bustamente. Em 12 de setembro de 1818, foi vendida ao coronel Carlos José Siqueira Quintanilha, pai de Belarmino Ricardo de Siqueira, futuro Barão de São Gonçalo. A partir de então, pai e filho passaram a adquirir fazendas do entorno incorporando-as à Fazenda do Engenho Novo. Esse processo ocorreu entre 1821 e 1871 e totalizou 14.739.912 metros quadrados. Herdada pelo Barão, era composta originalmente de um casarão com capela central. Esta foi a sede provisória da Freguesia de Nossa Senhora da Conceição de Cordeiros, desmembrando a regiáo dos atuais $2 .^{\circ}$ e $3 .^{\circ}$ distritos da freguesia de São Gonçalo, em 1844. O segundo casarão foi erguido em 1870 para acomodar o imperador Pedro II (Casadei, 1988; Molina e Silva, 1998, 2001, 2010). 
Figura 1. Primeira sede da Fazenda do Engenho Novo, construída entre finais do século XVIII e a primeira metade do século XIX. Ao centro, localizava-se a capela de Nossa Senhora da Conceição, São Gonçalo

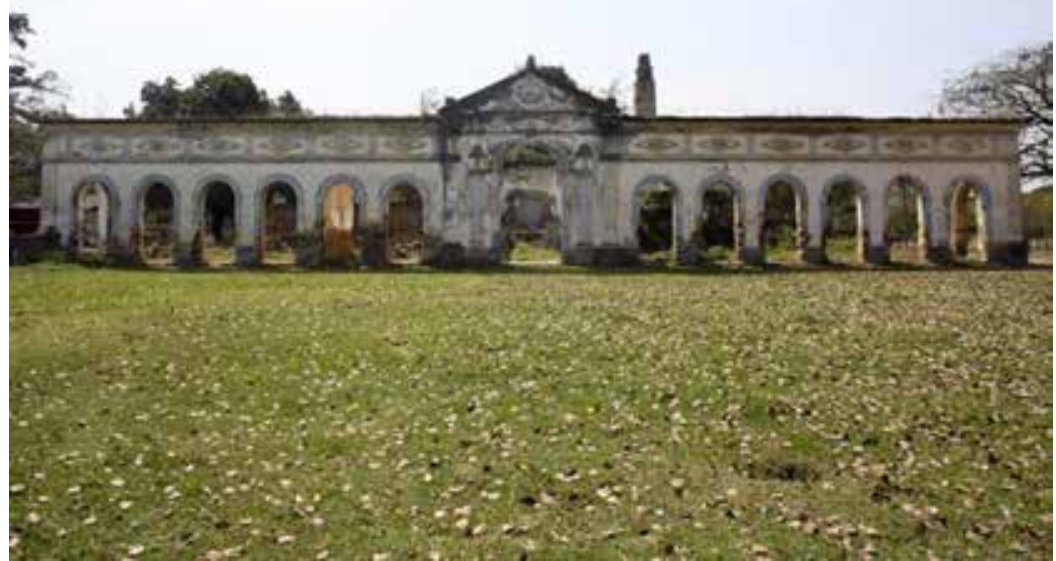

Fonte: Flávia Saleme, jul. 2012. Dispoível em: http://www.rj.gov.br/web/seh/ exibeconteudo?article-id=1018524. Acesso em: 26 ago. 2015.

Figura 2. Casarão construído em 1870 para abrigar o imperador Pedro II, São Gonçalo

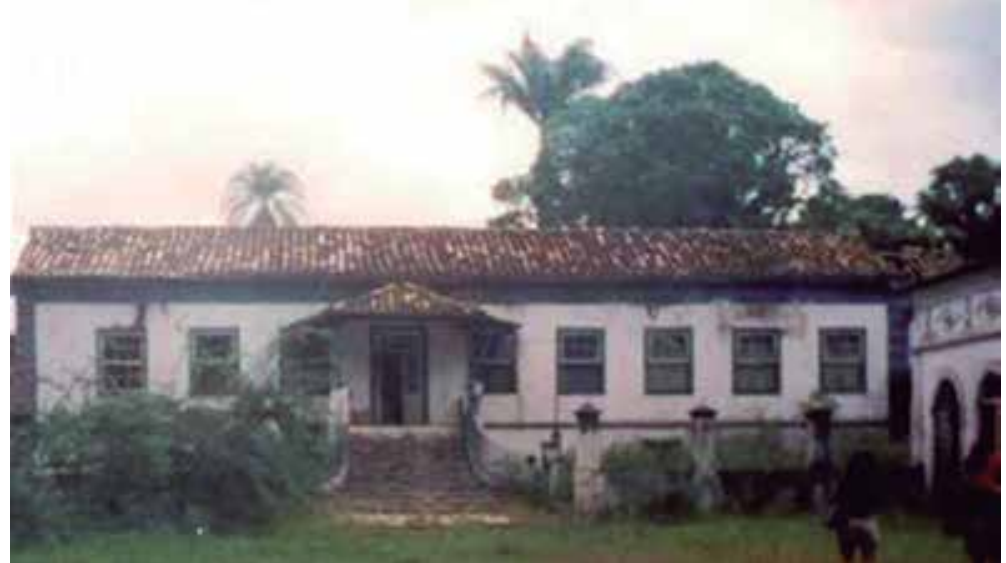

Fonte: Autor desconhecido, [década de 1990]. Disponível em: http://saogoncario.blogspot.com. br/2011/09/pontos-da-cidade-de-sao-goncalo-feliz.html. Acesso em: 26 ago. 2015. 
Figura 3. Ruínas do casarão erguido em 1870

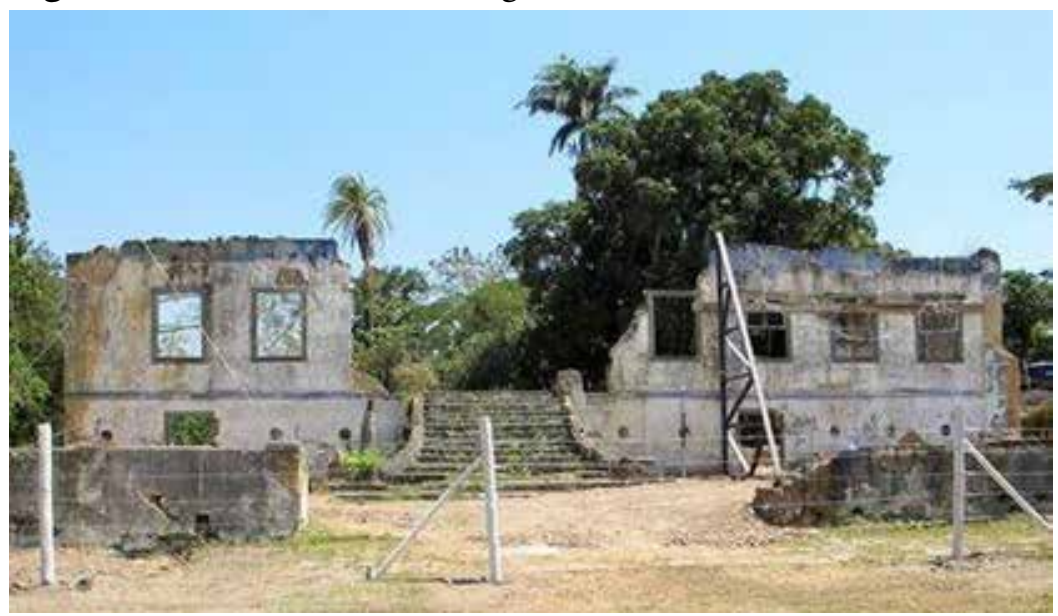

Fonte: Autor desconhecido, 2011. Disponível em: http://www.rj.gov.br/web/seh/ exibeconteudo?article-id=634001. Acesso em: 26 ago. 2015.

Falecido o baráo, em 1873, a fazenda passou para sua irmá que morreu pouco tempo depois. Em data incerta, foi arrendada pela família de Henrique Bessa, proprietário de madeireira local. Em data também desconhecida, Joaquim Serrado Pereira da Silva, o coronel Serrado, adquiriu a fazenda após ter-se casado com Cecília, sobrinha do Barão de São Gonçalo. Contraiu segundas núpcias, após o falecimento da primeira esposa, com Eponina de Abreu da Silva, com quem teve quatro filhos, entre eles José Baltazar Serrado. Durante o período em que esteve sob custódia da família Serrado, a fazenda passou a produzir laranjas. Na década de 1940, Sáo Gonçalo disputou com Nova Iguaçu o mercado produtor de laranjas (Palmier, 1940; Pereira, 1977). Na década de 1980, a fazenda foi vendida para Deusdérito Belmont, negociaçáo embargada pelo governo fluminense.

O terceiro período seria o "tempos de conflitos pela posse da Terra", incorporando o século XX e XXI. Após o falecimento do Barão de São Gonçalo, muitos dos antigos escravos e agrega- 
dos continuaram vivendo na Fazenda. Seus descendentes e outros passaram a ocupar as terras, gerando inúmeros conflitos de terras na regiâo. Assim, como forma de luta pelos sitiantes, fundaram, em 11 de junho de 1963, o Sindicato dos Trabalhadores Rurais de São Gonçalo. Esses conflitos perpassaram toda a segunda metade do século XX e chegaram ao século XXI. Na década de 1990, mais um agente se incorpora nesse litígio: o professor Homero Guião Filho, que criou a Fundaçáo Baráo de São Gonçalo e passou a pleitear na justiça a curadoria dos bens do patrono, incluindo aí a Fazenda do Engenho Novo. ${ }^{3}$ A partir de 2007, o Instituto de Terra do Estado do Rio de Janeiro regularizou a posse da terra da área da antiga fazenda. Esse é um tema pouco explorado e de suma importância, pois ocorreu em um período de expansão urbana/populacional da cidade que transformou o seu perfil de um município agrário para um dos principais centros da periferia da região metropolitana do Rio de Janeiro, entre 1950 e 1980.

\section{A Fazenda do Engenho Novo como um patrimônio cultural local}

A discussão sobre o patrimônio cultural brasileiro está na pauta de gestores e atores sociais desde o século XIX quando se buscava definir a identidade brasileira. Na década de 1920, foram pensados projetos de órgáos públicos destinados à proteção do patrimônio cultural brasileiro que inspiraram a organização do SPHAN, em 13 de janeiro de 1937, tendo como presidente Rodrigo de Melo Franco, o Dr. Rodrigo. Por cerca de trinta anos, imprimiu-se uma marca à discussão sobre o patrimônio: o período colonial foi eleito como o verdadeiro estilo histórico brasileiro (Chuva, 2009; Fonseca, 2009). Privilegiou-se o patrimônio material em detrimento do imaterial

Sobre a Fundação Barão de São Gonçalo, consultar: http://www.authorstream.com/ Presentation/Maristela2009-222713-Funda-o-Bar-de-SG-Entertainment-ppt-powerpoint/. Acesso em: 26 ago. 2015. 
- tratado como folclore (Vilhena, 1997) e deixado à margem da política de patrimonialização do IPHAN.

Atualmente a noção de patrimônio cultural vem englobar os aspectos materiais e imateriais. ${ }^{4} \mathrm{O}$ IPHAN vem se preocupando com a preservação de valores, práticas e saberes, tidos como tradicionais em suas comunidades, como o ofício das baianas de acarajé da Bahia, o ofício dos mestres de capoeira, a festa do Divino de Paraty, o frevo, entre outros. Mesmo em relação ao patrimônio material foram ampliadas as concepçôes estilísticas para julgamento dos bens, incorporando, por exemplo, as obras de Oscar Niemeyer.

Nesse sentido, seguindo as novas perspectivas, podemos definir o patrimônio cultural como:

Por patrimônio cultural, compreende-se um conjunto de bens materiais - a saber, prédios, conjuntos urbanos, paisagens e sítios arqueológicos entre outros - e imateriais - classificados como saberes, modos de fazer, formas de expressão e celebraçōes - considerados relevantes para a constituição dos valores de um grupo social. Estes valores embasam os códigos com os quais se aprende a viver e se relacionar com o mundo que nos cerca. [...]

A simples sobrevivência ao tempo não assegura, por si só a condição de transformar em patrimônio cultural um objeto, um vestígio material, um acervo arquitetônico ou uma manifestação artística. Esses elementos só ganham a condição de patrimônio porque foram construídos sentidos contemporâneos para eles e assim sendo, foram incorporados como elementos importantes para a coletividade no tempo presente (Conduru et al., 2013, pp. 13-4).

4 A definição de patrimônio cultural proposta pelo IPHAN pode ser consultada em: http://portal.iphan.gov.br/pagina/detalhes/218. Acesso em: 26 ago. 2015. 
Essa definição de patrimônio coloca em xeque algumas ideias consolidadas. $\mathrm{O}$ senso comum geralmente identifica como elementos importantes da localidade, ou seja, seus patrimônios, as construçóes antigas geralmente ligadas ao poder público - sedes das prefeituras, câmaras de vereadores e fóruns -, às instituições templos, sedes associaçóes e de clubes -, ou que tenham abrigado personagens de relevo local, regional ou nacional. O critério da antiguidade também é importante. Outro dado agregado a essa perspectiva é de que cabe ao poder público identificar e proteger um bem patrimonial. Se assim o fosse, deveríamos nos perguntar por que tantas construçôes antigas encontram-se abandonadas e em estado de arruinamento em toda parte?

No que concerne à Fazenda do Engenho Novo, a oficialização enquanto patrimônio já ocorreu a nível local e estadual.

A produção historiográfica reconhecida e mais amplamente divulgada sobre a cidade - como os livros de Luiz Palmier, Homero Guiáo Filho, Salvador Mata e Silva e Evadyr Molina e Maria Nelma de Carvalho Braga - referendam a Fazenda com patrimônio local e historiam-lhe as origens e o esplendor. É essa produção que municia o parco material didático que circula pela cidade assim como os sites e materiais de divulgaçáo produzidos pelos órgãos públicos e associaçóes locais. São essas as fontes que embasam a ficha técnica desse bem presente no Inventário de oferta turística do município de São Gonçalo, realizado em 2004 pela então Secretaria Municipal de Esporte, Lazer e Turismo. ${ }^{6}$

O reconhecimento pelo Instituto Estadual do Patrimônio Cultural do Rio de Janeiro ocorreu em 1998. Naquele momento,

5 Uma perspectiva diferente foi produzida em 2006 pelos Grupos de Pesquisa História de São Gonçalo: Memória e Identidade e Oficinas da História, que elaboraram a Caixa de história: São Gonçalo (Fernandes, 2006).

6 Disponível em: http://www.semeltur.com.br/inventarioturistico/html/. Acesso em: 26 ago. 2015. 
o conjunto arquitetônico da Fazenda do Engenho Novo do Retiro foi tombado, reconhecendo seu valor histórico e estilístico.

$\mathrm{O}$ reconhecimento oficial, referendado pelo INEPAC e pela administração municipal, representam uma das facetas da patrimonialização da Fazenda do Engenho Novo. No entanto, apenas o reconhecimento oficial não foi suficiente para torná-lo um bem patrimonial. A chancela governamental não impediu que as dependências da sede da Fazenda fossem invadidas, o mobiliário e demais utensílios - alguns do século XIX - saqueados e as construções abandonadas, nas décadas de 1990 e 2000. A deterioração dos prédios foi acompanhada de uma caça ao tesouro. Naquele momento, surgiu a lenda que o barão havia enterrado ouro na propriedade. Exploradores esburacaram o primeiro nível do casarão, erguido em 1870, à busca de tal tesouro, e, com isso, abalaram-se as estruturas do casarão centenário. $\mathrm{O}$ terreno próximo também foi alvo de escavaçôes. Não encontraram ouro, mas sim areola que passou a ser extraída e comercializada na construção civil local. $\mathrm{O}$ abandono foi tanto que o prédio construído na segunda metade do século XIX praticamente ruiu restando apenas a escadaria de acesso e partes da fachada.

Nos últimos tempos, a comunidade local vem se organizando e mobilizando uma série de agentes, como departamentos governamentais estaduais e municipais, sindicatos, associaçóes de moradores e de produtores, universidades, entre outros, buscando a valorização das ruínas, a preservação e recuperação dos remanescentes das construçôes da sede da fazenda. Essa busca representa o reconhecimento local de que aquelas construções são significativas no processo de reconhecimento de si, nos processos de construção identitária local. 


\section{Para náo concluir}

A Fazenda do Engenho Novo vem se configurando como um instigante objeto de pesquisas. A produção bibliográfica e a história local levantada indicam uma série de temáticas que tornam o objeto um manancial de estudos para uma equipe interdisciplinar: geógrafos, geólogos, biólogos, sociólogos, antropólogos, historiadores, turismólogos etc. Um potencial ainda pouco explorado, mas que vem instigando a atenção de alguns estudiosos. Essa atenção não se dá exclusivamente por ser este um objeto de estudos científicos, mas sim por ter um papel social. A luta de mais de meio século levou aquela comunidade, fixada nas terras do barão de São Gonçalo, à obtenção da regularização fundiária e, com isso, ao reconhecimento de seus direitos de construçáo de uma vida estável e melhor. A riqueza histórica desse sítio está para além dos remanescentes das construçôes que abrigaram a família imperial e das instalaçóes produtoras de gêneros agrícolas. Os bens de pedra e cal são ícones, símbolos da luta histórica daqueles homens e mulheres que tiraram da terra o seu sustento e deram seu suor para que aquele espaço se tornasse o seu lar. Se por um lado temos o reconhecimento oficial - a proteção do INEPAC e a inclusão da Fazenda entre os bens locais pela Secretaria Municipal de Esportes, Lazer e Turismo - de que aquelas construçóes compóem um marco histórico para a localidade, pelas experiências ali vivenciadas, especialmente como exemplar das vivendas da nobreza imperial em terras gonçalenses, os movimentos pela posse da terra e pela preservaçáo dos prédios, levados a cabo pela comunidade local, por outro lado, demonstram que aquele espaço foi ressignificado e apropriado pelos lavradores e sitiantes que o tornaram emblemático na construção de suas identidades. 


\section{Referências}

ARAÚJO, J. S. A. P. "Relação das sesmarias da capitania do Rio de Janeiro, extraída dos livros das sesmarias e registros do cartório do tabelião Antônio Teixeira de Carvalho, de 1565 a 1796. Revista do Instituto Histórico e Geográfico Brasileiro, Rio de Janeiro, t. 63, parte 1, Rio de Janeiro, 1900, pp. 93-153.

AZEVEDO, C. V. e GODOY, K. E. "Turismo, memória e patrimônio no circuito turístico digital da Fazenda Engenho Novo". Anais do 6. ${ }^{\circ}$ Foro Latinoamericano "Memoria e Identidade". Montevideo: Signo Centro Interdisciplinario, 2009.

$\mathrm{e}$

. "Hacienda Engenho Novo: el destino de un bien patrimo-

nial delante de las intervenciones y cambios producidos en su territorio, a partir de politicas de preservación y de incentivo". In OLIMPIA, N. (org.). Paisaje cultural urbano e identitad territorial. Roma: Aracne editrice S.r.l., 2012, pp. 486-98.

BRAGA, M. N. C. O município de São Gonçalo e suas histórias. S.l.: Edição Independente, 1997.

CAETANO, A. F. P. Entre a sombra e o sol. A Revolta da Cachaça e a crise politica fluminense. Rio de Janeiro, 1640-1667. Maceió: Q-Gráfica, 2009.

CASADEI, T. "Barão de São Gonçalo". In (org.). A Imperial Cidade de Nictheroy. Niterói: Serviço Gráfico Impar, 1988.

CONDURU, R. L. T. et al. Patrimônio cultural no leste fluminense. História e memória de Itaboraí, Rio Bonito, Cachoeiras de Macacu, Guapimirim, Tanguá. Rio de Janeiro: EdUERJ, 2013.

CHUVA, M. R. R. Os arquitetos da memória. Sociogênese das práticas de preservação do patrimônio cultural no Brasil (anos 1930 e 1940). Rio de Janeiro: Ed. UFRJ, 2009.

FERNANDES, R. A. N. "São Gonçalo, uma história”. In et al. (orgs.). Caixa de história: São Gonçalo. Rio de Janeiro: Imprinta Express, 2006, pp. 61-8.

. Historiografia e identidade fluminense: a escrita da história e os usos do passado no Estado do Rio de Janeiro entre as décadas de 1930 e 1950 (tese). Pontifícia Universidade Católica, 2009.

FONSECA, M. C. L. O patrimônio em processo. Trajetória da política federal de preservação no Brasil. Rio de Janeiro: Ed. UFRJ, 2009.

FREIRE, R. C. B. L. Poder e sociedade na [trans]formação da cidade (monografia). UERJ/FFP, 2002. 
GODOY, K. E. "Circuito turístico na Fazenda Engenho Novo. Possibilidades para a preservação do patrimônio cultural, a valorização da comunidade local e a profissionalização de atividades geradoras de renda". Anais do XXVI Simpósio Nacional de História - ANPUH. São Paulo, 2011.

GUIÃO FILHO, H. T. História de São Gonçalo. São Gonçalo: s.n., 1968.

GUIMARÃES, M. L. S. "Reinventando a tradição: sobre antiquarido e escrita da história”. Humanas, 23 (1/2), 2000, pp. 111-43.

LE GOFF, J. "Documento/monumento". In (org.). História e memória. Campinas: Ed. Unicamp, 2003.

LIMA, N. T. Um sertão chamado Brasil. Rio de Janeiro: Revan/IUPERJ/ UCAM, 1999.

KOSSOY, B. A fotografia como fonte histórica. São Paulo: Museu da Indústria, Comércio e Tecnologia de São Paulo, 1980.

MAUAD, A. M. "Através da imagem. Fotografia e história, interfaces". Tempo, v. 1, n. 2, 1996, pp. 73-98.

MEIHY, J. C. S. B. Manual de história oral. São Paulo: Edições Loyola, 2002.

MENDES FILHA, N. F. e VARELLA, M. V. M. São Gonçalo, sua história e seus monumentos. Niterói: Disk Cópia - Gráfica Rápida, 2000.

MICHELET, J. História da Revolução Francesa. São Paulo: Companhia das Letras, 1989.

MOLINA, E. e SILVA, S. M. São Gonçalo no século XVI. Rio de Janeiro: Companhia Brasileira de Artes Gráficas, 1995. $\mathrm{e}$ São Gonçalo no século XVII. Rio de Janeiro: Companhia Brasileira de Artes Gráficas, 1997. e ___ São Gonçalo no século XVIII. Niterói: Muiraquitã, 1998. e __. A fazenda do Engenho Novo do Retiro. Niterói: Edições Silveiro J. C. Moreira, 2001. e _ـ São Gonçalo no século XIX. São Gonçalo: São Gonçalo Letras, 2010.

MOMIGLIANO, A. Raizes clássicas da historiografia moderna. Bauru: Edusc, 2004.

MOTTA, K. A. P. Fazenda do Engenho Novo, um patrimônio histórico em São Gonçalo (monografia). UERJ/FFP, 2013.

NOVAIS, A. F. O. Retrato da Boa Sociedade (monografia). Universidade do Estado do Rio de Janeiro, 2000.

OLIVEIRA, R. A. 2012. "Um estudo sobre família escrava em São Gonçalo (RJ) 1820-1870". Anais do 1. ${ }^{\circ}$ Seminário Fluminense de Pós-Graduandos em História. Rio de Janeiro, 2012.

PALMIER, L. São Gonçalo, cinquentenário: história, geografia, estatística. Rio de Janeiro: Serviços Gráficos do IBGE, 1940. 
46 O rural em regióes metropolitanas: a Fazenda Engenho Novo, Sáo Gonçalo

PEREIRA, W. Cana, café e laranja. História econômica de Nova Iguaçu. Rio de Janeiro: Fundação Getúlio Vargas/Secretaria Estadual de Educação do Rio de Janeiro, 1977.

REZNIK, L. "Qual o lugar da história local?”. Anais do V Taller Internacional de Historia Regional y Local. Havana/Cuba, Mimeo, 2002.

THOMPSON, E. Costumes em comum. São Paulo: Companhia das Letras, 1998a.

THOMPSON, P. A voz do passado. História oral. São Paulo: Paz e Terra, $1998 \mathrm{~b}$.

VILHENA, L. R. Projeto e missão: o movimento folclórico brasileiro (19471964). Rio de Janeiro: Funarte/FGV, 1997. 